\title{
Spatial resolution and peak-pressure-change measurement accuracy
}

Todd C Pataky

From 3rd Congress of the International Foot and Ankle Biomechanics Community

Sydney, Australia. 11-13 April 2012

\section{Background}

It has been suggested that plantar pressures should be measured at $\sim 6.2 \mathrm{~mm}$ to accurately characterize local maxima [1], and it has been shown that sensor widths of $10 \mathrm{~mm}$ can cause a $30 \%$ pressure underestimation at the metatarsal heads [2]. However, these results assume that pressure maxima, not maxima changes, are of primary interest. The purpose of this study was to examine how spatial resolution affects accuracy when measuring local maxima vs. changes in local maxima.

\section{Methods and materials}

A pressure pulse model (Figure 1) was generalized from [2] for force $(F)$ and wavelength $(\lambda)$ as:

$$
f(x, y)=\frac{F}{\lambda^{2}}\left(1+\cos \left(\frac{2 \pi}{\lambda} x\right)\right)\left(1+\cos \left(\frac{2 \pi}{\lambda} y\right)\right)
$$

where the maximum pressure $\left(p^{*}\right)$ is $4 F \lambda^{-2}$, and the measured pressure $(p)$ has an analytical solution depen-

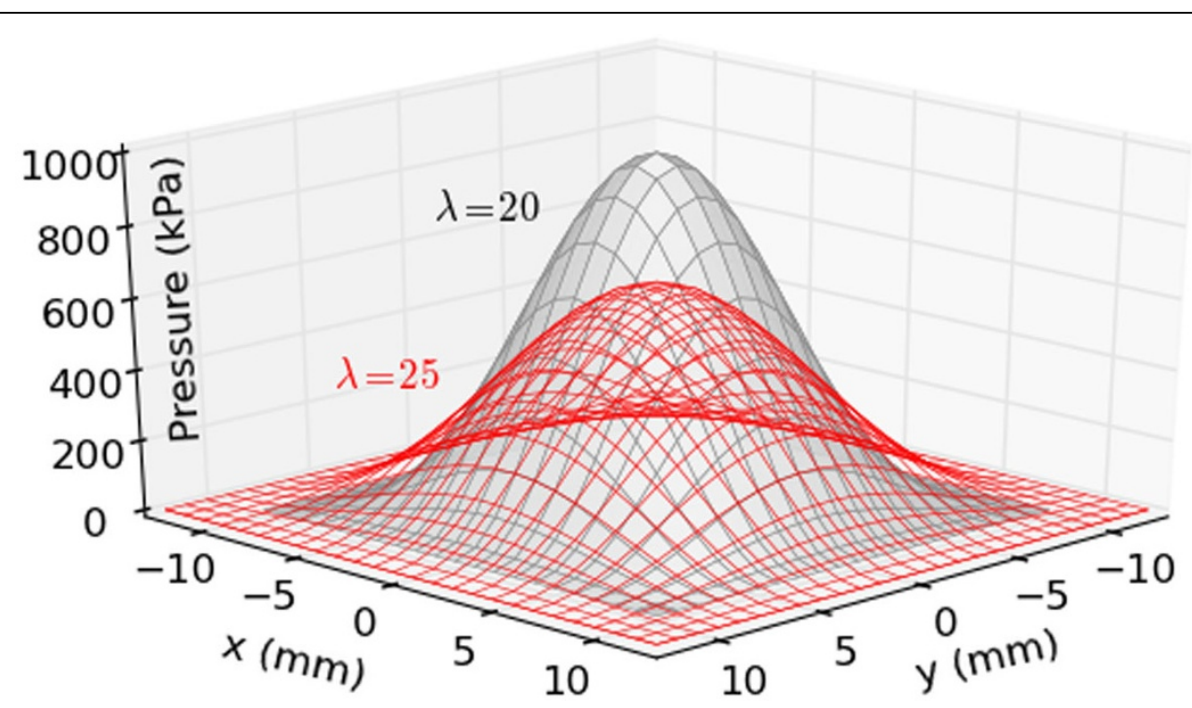

Figure 1 Pressure model (Eqn.1). Example pulses of $\lambda=20$ and $25 \mathrm{~mm}$, with maxima of $\mathrm{p}^{*}=1000 \mathrm{kPa}$ and $640 \mathrm{kPa}$, Total force $=100 \mathrm{~N}$.

Correspondence: tpataky@shinshu-u.ac.jp

Department of Bioengineering, Shinshu University, Ueda, Nagano, 386-8567, Japan 


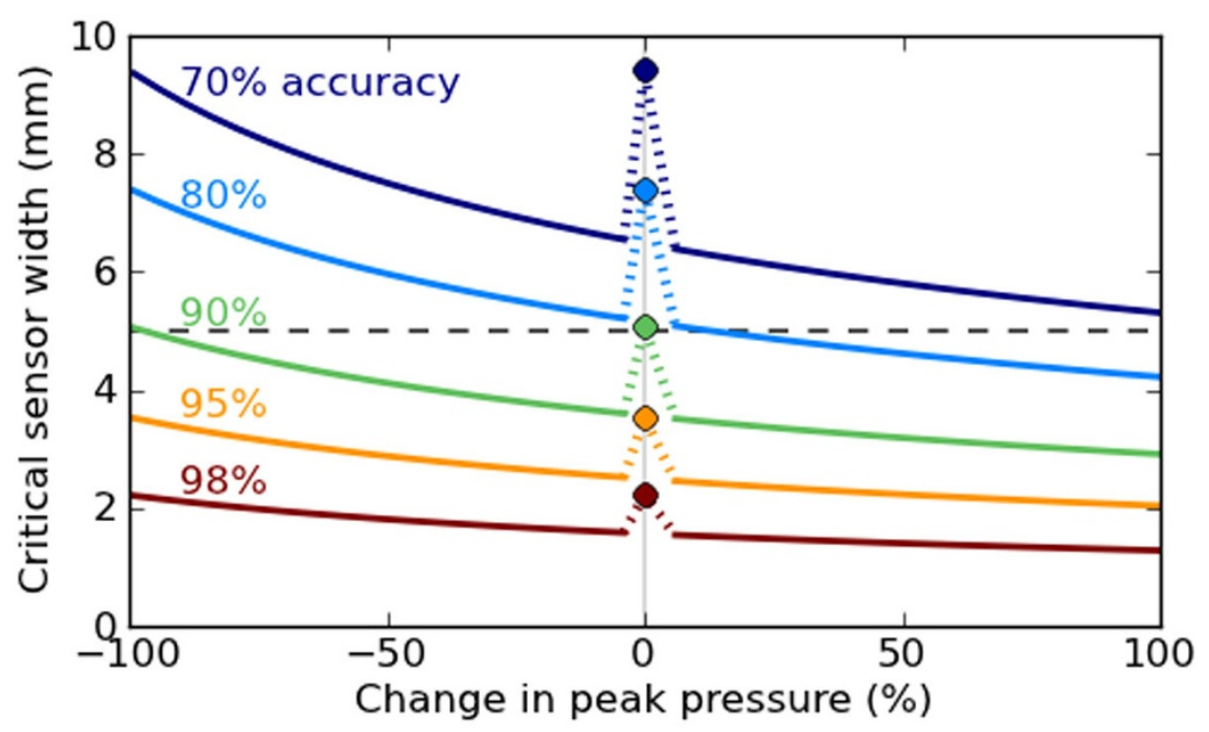

Figure 2 Critical sensor width needed to achieve given accuracies for local maxima (solid dots), and maxima changes (solid lines).

dent on sensor width $w$. The measurement accuracy of local-maxima and local-maxima-changes are $p / p^{*}[2]$, and $\left(p_{1}-p_{2}\right) /\left(p^{*}{ }_{1}-p^{*}{ }_{2}\right)$, respectively, where ' 1 ' and ' 2 ' denote pulses with different wavelengths. To mimic insole-padding intervention, where total force is not expected to change, $F$ was a constant $100 \mathrm{~N}$ and $\lambda$ was varied from $20 \mathrm{~mm}$ [2]. Numerical optimization was used to find the critical sensor width that yielded various target accuracies for both local-maxima and a variety of local-maxima-changes $(-100 \%$ to $+100 \%$ change) .

\section{Results}

Results reveal that a target accuracy of $90 \%$ requires 5 $\mathrm{mm}$ resolution for local peak pressures (Figure 2), and that pressure-changes at $90 \%$ accuracy require resolutions of $4.1 \mathrm{~mm}$ and $3.2 \mathrm{~mm}$, for changes of $-50 \%$ and $+50 \%$, respectively. The reason is intuitive: the true difference pulse has higher frequency components than the original pulses, so pressure-change accuracy will be lower for all changes $>-100 \%$.

\section{Conclusion}

This study has shown that, to achieve a given measurement accuracy, higher spatial resolutions are needed to measure local-pressure-maxima-changes than singlemaxima. The main limitations are that pressure pulses are not, in general, constrained to have constant force and that broader (i.e. non-local) pressure changes were not considered.

\section{References}

1. Davis B, Cothren R, Quesada P, Hanson SB, Perry JE: Frequency content of normal and diabetic plantar pressure profiles: implications for the selection of transducer sizes. J Biomech 1996, 29:979-983.

2. Lord M: Spatial resolution in plantar pressure measurement. Med Eng Phys 1997, 19:140-14.

doi:10.1186/1757-1146-5-S1-030

Cite this article as: Pataky: Spatial resolution and peak-pressure-change measurement accuracy. Journal of Foot and Ankle Research 2012 5(Suppl 1):030.
Submit your next manuscript to BioMed Central and take full advantage of:

- Convenient online submission

- Thorough peer review

- No space constraints or color figure charges

- Immediate publication on acceptance

- Inclusion in PubMed, CAS, Scopus and Google Scholar

- Research which is freely available for redistribution

Submit your manuscript at www.biomedcentral.com/submit 